\title{
Review
}

Respiration 2015;89:82-87

DOI: $10.1159 / 000369474$

\section{From Breathing to Respiration}

\author{
Jean-William Fitting \\ Department of Respiratory Medicine, Lausanne University Hospital, Lausanne, Switzerland
}

\author{
Key Words \\ Historical review · Respiratory physiology · Breathing · \\ Respiration · Oxygen
}

\begin{abstract}
The purpose of breathing remained an enigma for a long time. The Hippocratic school described breathing patterns but did not associate breathing with the lungs. Empedocles and Plato postulated that breathing was linked to the passage of air through pores of the skin. This was refuted by Aristotle who believed that the role of breathing was to cool the heart. In Alexandria, breakthroughs were accomplished in the anatomy and physiology of the respiratory system. Later, Galen proposed an accurate description of the respiratory muscles and the mechanics of breathing. However, his heart-lung model was hampered by the traditional view of two non-communicating vascular systems - veins and arteries. After a period of stagnation in the Middle Ages, knowledge progressed with the discovery of pulmonary circulation. The comprehension of the purpose of breathing progressed by steps thanks to Boyle and Mayow among others, and culminated with the contribution of Priestley and the discovery of oxygen by Lavoisier. Only then was breathing recognized as fulfilling the purpose of respiration, or gas exchange. A century later, a controversy emerged concerning the active or passive transfer of oxygen from alveoli to the blood. August and Marie Krogh settled the dispute, showing that passive diffusion was sufficient to meet the oxygen needs.

(c) 2014 S. Karger AG, Basel
\end{abstract}

\section{The Breath in Ancient Greek Medical Schools}

To us, the act of breathing, i.e. the flow of air in and out of the nose or mouth, evidently serves the purpose of respiration, i.e. the exchange of oxygen and carbon dioxide. However, our understanding of breathing is the result of a long succession of often erring efforts and controversies. Already in ancient civilizations, breathing was recognized as a manifestation of life. Besides, it was thought that the soul, or the principle of life, must lie somewhere in the body, and the heart was considered as the seat of the soul in several civilizations such as in ancient Egypt and India [1,2]. For a long time, the relation between the breath and the heart was an elusive enigma.

In early Greek thought, such as in Homer, man had two souls: the psyche was the individual and immortal soul located in the head, whereas the thymos (the later pneuma) was located in the chest, breathed in at the first breath and out at the last. The early Greek schools of medicine differed in their comprehension of breathing. The cerebrocentrist tradition held that the soul originated from ambient air (pneuma), which was inspired through the nose into the brain and then transported to the body by the vessels. In contrast, the cardiocentrist view held that the heart was the seat of the soul and implied anatomical pathways between the lungs and the heart $[1,3]$.

Hippocrates (460-370 BC) founded a medical school on the island of Cos where chest diseases and interventions were taught, including direct auscultation and evacuation of chest collections. Clinical descriptions reported

\section{KARGER 125}

C 2014 S. Karger AG, Basel

0025-7931/14/0891-0082\$39.50/0
Prof. Jean-William Fitting

Service de Pneumologie, CHUV

$\mathrm{CH}-1011$ Lausanne (Switzerland)

E-Mail jwfitting@bluewin.ch 
the frequency and amplitude of breathing and made reference to periodic breathing. However, in the absence of human dissection the Hippocratic school was cerebrocentrist, and breathing was not associated with the lungs $[1,4]$.

Empedocles (490-430 BC) was a physician, philosopher and poet living in Agrigentum in Sicily. He held that the world was constituted of four elements - earth, air, fire and water - and that all matter contained tiny channels or pores allowing the exchange of elements. The movements of elements were governed by attraction and repulsion. For him, movement of air occurs through the pores of the skin. The blood is first attracted in the periphery of the body by the external cosmos fire. The surge of blood into the proximal parts of skin pores forces air to escape through the distal parts of the pores. Then the peripheral blood cools down and is drawn inside again, attracting air back through the pores of the skin. To explain the ebb and flow of blood and air through the skin, Empedocles used the analogy of the clepsydra, a container with holes in the bottom used to transport liquids. Besides, to him the air inhaled through the nose served to cool the internal heat of the body [4].

A somewhat similar concept was advocated by Plato (428-347 BC), who founded the Academy of Athens. Plato described the three souls of man: the highest and rational soul was in the head, the second was the source of courage, originated from breathing and was located in the heart, and the lowest was associated with nutrition and physical needs and was in the liver. The diaphragm served as a barrier separating the inferior soul from the other two $[1,4]$. The lungs were described as perforated by cavities like a sponge and their function was to cool the excessive heat of the heart. According to Plato, breathing is due to the interior fire forcing air to escape through the nose and mouth. Because of the absence of any existing void, the exhaled air forces surrounding air to enter the body through the pores of the skin. Then the outside air cools down and the inside air warms up, the latter escaping through the skin, forcing the surrounding air to enter back through the nose and mouth. Thus, for Plato breathing is a circular model combining the passage of air through the nose and the skin $[3,4]$. The hypothesis of cutaneous respiration was not far-fetched if we remember that it plays a major role in carbon dioxide exchange in amphibians [5].

Aristotle (384-322 BC) was the son of a physician, studied under Plato and became the tutor of Alexander the Great. He believed that the heart was the site of innate heat and pneuma. On the basis of observations on ani- mals but without access to human dissection, he was the first to describe the right and left parts of the heart. He criticized the theories of Empedocles and Plato on breathing. Air was only air breathed in and out to cool the heat of the heart. For him, the lungs first expand because of the heat and then are filled with fresh air. When the lungs cool down they contract and expel air outside. The thorax moves only as a consequence of lung movements and the diaphragm plays no role in breathing. By that time, muscles were thought to protect from cold and injuries but had no relation with motion $[1,4]$.

\section{The Hellenistic Breakthroughs}

Following the end of Alexander's empire, Alexandria became the dominant commercial and cultural centre with its University opening in 322 BC. Anatomy and physiology progressed markedly thanks to a liberal use of human dissection and seemingly of human vivisection as well. A major breakthrough was the description of the nervous system with the brain at its centre and the muscles as the source of motion. Knowledge of the vessels progressed as well. Earlier reports mentioned two main parallel vessels (vena cava and aorta) connected to the different viscera and extending to the brain. Then veins and arteries were distinguished, forming two non-communicating systems. The venous tree was thought to take its origin in the liver, which was the blood-forming organ, and was transporting blood to all organs through a unidirectional flow. The arterial system consisted of air-carrying vessels and included the trachea, the lungs, the heart, and the arteries themselves. The notion of air-containing arteries probably resulted from the killing of animals by cutting their throat, which allowed the blood to escape from arteries before dissection was performed. No communication existed between arteries and veins.

Herophilus (335-280 BC) led the School of Anatomy and Medicine of Alexandria and was the first to discover the cardiac valves. For him, breathing consists of air inspired to the lungs, then transported to the heart and via arteries to the body. Air then follows the same way back to be exhaled, although this model appears problematic in the presence of unidirectional cardiac valves. His younger colleague Erasistratus (304-257 BC) was the first to describe the diaphragm as a muscle responsible for breathing. In contrast to Aristotle, he thought that the pneuma had to be inspired from ambient air, and he held that arteries contained only pneuma without blood. To explain how blood could surge from wounded arteries, he 
hypothesized that communication existed between small veins and small arteries, allowing blood to flow back in case of an arterial lesion. Thus, a traditional erroneous view of arteries led him to postulate the existence of capillaries $[4,6]$.

\section{Galen's Legacy}

Galen (129-201 AD) was born in Pergamon, a Greek city in Asia Minor, where he studied philosophy and medicine before leaving for Smyrna and Alexandria. He then returned to Pergamon where he was appointed physician to the gladiators, and finally pursued a medical career in Rome after being called by the Emperor Marcus Aurelius. By his time, human dissection was no longer practiced and he performed extensive observations and experiments in animals. He left abundant writings where he describes his studies and his temper, revealing himself as self-centred and contentious with his opponents $[7,8]$.

Galen gave a detailed description of the upper airways and thoracic innervation, as well as of the anatomy of the diaphragm and other respiratory muscles. Using a living pig model, he reported the effects of pneumothorax and of sectioning intercostal or phrenic nerves. The whole represents a comprehensive and accurate physiology of the diaphragm and other respiratory muscles [8]. With regard to the heart and lungs, Galen adopted the old idea of a double vascular system, but in contrast to Erasistratus he held that arteries contained blood. There, Galen faced a problem: with two separate vessel systems, how could the arteries be filled with blood? As he refuted the hypothesis of Erasistratus of arterio-venous communication, he postulated the existence of pores in the interventricular septum allowing the passage of blood to the left ventricle and to the arteries. Still far from the concept of pulmonary circulation, he thought that escaping waste vapours travelled back from the arteries to the lungs, resulting in a bidirectional flow in pulmonary veins between the lungs and the heart. Ironically, Galen's modern comprehension of diaphragm function was forgotten, whereas his erroneous cardiopulmonary model was respectfully transcribed throughout centuries $[6,8]$.

\section{The Stagnation and Revival of Respiratory Science}

At Galen's death, the comprehension of breathing came to a halt for a millennium. Although Galen worked and died in Rome, the Romans had only a superficial knowledge of Greek science. During the Middle Ages, dissection was prohibited and Galen's writings were repeatedly copied, condensed and translated into Arabic and other oriental languages, mainly from Alexandrian sources $[7,9]$. By the end of the 13th century, human dissection became standard practice in European universities, but at the onset it only served to illustrate ancient texts originating from Arabic and Byzantine sources. These sources were diverse and conflicting and the texts were often corrupt by repeated copying. Nevertheless, the influence of the Ancients was such that anatomists evoked degeneration of the human body when their observations contradicted the texts.

Leonardo da Vinci (1452-1519) produced detailed drawings of the bronchial tree, lungs and respiratory muscles, showing among others the increasing calibre of bronchi with lung inflation. He was the first to describe lung residual volume existing after a complete exhalation. However, based on his observation of tracheal innervation he erroneously concluded that the human voice resulted from tracheal constriction [10].

Until the 16th century, the notion of blood circulation was unknown and the venous blood flow was centrifugal. Pulmonary circulation was discovered first, but in a kind of stuttering way. Ibn al-Nafis (1210-1288) was a physician living in Egypt. While commenting on Avicenna's Canon, and without access to dissection, he denied the existence of pores in the cardiac septum and concluded that blood passed from the right to the left heart through the lungs. However, his statement remained unknown and was not translated until the end of the 16th century $[9,11]$. Andreas Vesalius (1514-1564) was born in Brussels and became Professor of Anatomy at Padua. He denied the existence of Galen's septal pores, but being an anatomist he did not foresee the physiological consequences of his observation. Michael Servetus (1509-1553) was a Spanish physician and theologian. He was a radical protestant, a rival of Calvin, and was finally arrested, tried and burnt in Geneva. Servetus attempted to solve the theological problem of the entrance of Holy Spirit into the blood. He considered the lungs a suitable interface and by reasoning only concluded that the blood circulated through the lungs in order to transport the spirit to the whole body. Finally, Realdo Colombo (1515-1559) succeeded Vesalius as Professor of Anatomy at Padua. Unaware of the works of Ibn al-Nafis and Servetus, he definitively established the concept of pulmonary circulation $[11,12]$. For a while, the newly discovered pulmonary circulation coexisted with the traditional view of two distinct systemic vascular systems, each with its ebb and flow
Fitting 
of blood, until the discovery of systemic circulation was published in 1628 by William Harvey [11, 13]. In 1661, Marcello Malpighi used the recently invented compound microscope to publish the first description of pulmonary alveoli and capillaries. In spite of a perfect comprehension of lung microscopic anatomy, he did not envisage its gas exchange function and thought that its role was to mix the mass of the blood [14]. At this point in the 17th century, one knows how breathing occurs and blood circulates, but not why.

\section{The Path to Oxygen Discovery}

In 1644, Evangelista Torricelli built the first mercury barometer showing that air could be weighed, and wrote his striking conclusion: 'We live submerged at the bottom of a sea of air'. He understood that a vacuum existed above the column of mercury, but this idea remained confidential for fear of persecution for heresy, as the Catholic Church had adopted Aristotle's dogma that no vacuum existed.

In Oxford and in London, two groups developed a 'new experimental philosophy' which led to the foundation of the Royal Society in 1662. Robert Boyle (16271691) built an air pump and conducted numerous experiments showing that the withdrawal of air from a closed chamber led to the extinction of a candle flame or of an animal life. Boyle concluded that air was necessary to fire and life, but did not speculate further [15]. Robert Hooke (1635-1703) reported an elaborate animal experiment using open chest surgery. He used two bellows in series with the second one connected to a dog's trachea, and he made multiple perforations of the pleura. He could show that life could be sustained by a continuous flow of air to the trachea which escaped through the pleural holes, even without the motion of the chest. Thus, death was not caused by the cessation of breathing movements, but by the lack of fresh air [16]. A member of the same group, John Locke (1632-1704) hypothesized that air mixed with the blood to make it more reactive to sustain life. After the body consumed the volatile part of the blood, the latter was sent back to the lungs and heart. Based on the observation of a dish where only the superficial layer of blood was red, Locke concluded that the mixing of blood with air occurred in the lungs. While close to understanding lung gas exchange, he abandoned experiments and turned to clinical practice [17].

John Mayow (1641-1679) studied in Oxford and became Boyle's assistant in 1666. Arriving as a junior on the scientific scene, he capitalized on his predecessors' works and was able to formulate a complete explanation of breathing. Mayow repeatedly used an experimental model where he placed a candle or a small animal under a cupping glass whose bottom was immersed in water. $\mathrm{He} \mathrm{ob-}$ served two phenomena: the level of water was rising in the cupping glass, and the candle flame went out or the animal died while there was still plenty of air in the glass. In his Tractatus Quinque published in 1674, Mayow wrote: 'The chief use of respiration is that particles of a certain kind, absolutely necessary for the support of animal life, may be separated from the air by means of the lungs and mixed most minutely with the mass of the blood'. He also hypothesized that this 'arial salt' was the source of body heat when combined with combustible material, particularly in muscles. Interestingly, his correct conclusion stemmed from a biased experiment. A burning candle or a living animal produces almost as much carbon dioxide as the amount of oxygen consumed. The water level rose only because the highly soluble carbon dioxide dissolved in water. Had he used mercury in place of water, he would not have noticed a change in its level. Mayow was close to discovering oxygen, but he left research at the age of 33 and turned to medical practice [18].

At the end of the 17th century, scientists erred for a while on the wrong path of the so-called 'phlogiston' theory. Combustible substances were said to be rich in phlogiston, a material which escaped into the air when burning. The extinction of a flame in a closed space was due to the finite capacity of air to absorb phlogiston.

The two major characters involved in the discovery of oxygen saw their fate bound to the French Revolution. Joseph Priestley (1733-1804) originated from a strict Calvinist family near Leeds. After studying languages, mathematics and religion, he was ordained a minister. In 1774, he isolated an unknown air by heating mercury. He noted that this air allowed a candle to burn more brightly and prolonged the life of an enclosed animal. Influenced by the current prevailing theory, he called it 'dephlogisticated air', thinking that it could absorb more phlogiston. Born in Paris, Antoine Laurent de Lavoisier (1743-1794) studied chemistry, geology, astronomy, mathematics, and law and developed an interest in questions of public health. With the help of his wife Marie-Anne-Pierrette, he worked on vegetal and animal respiration. During a dinner in Paris, Priestley told him about his experiment, but Lavoisier rejected the phlogiston theory. On the contrary, he postulated that air was made of 'vital air' which he named 'oxygen' (acid forming) and of nitrogen which he named 'azote' (without life) in French. He was the first to measure 
oxygen consumption and carbon dioxide production, reporting data at rest, after a meal and at work. With Lavoisier, breathing was finally recognized as fulfilling the purpose of respiration, or gas exchange. In the same year of 1794, Priestley left for Pennsylvania after being persecuted for his support of the French Revolution, and Lavoisier was executed by guillotine on the grounds of his previous role of tax collector under the Monarchy [19].

\section{The Oxygen Secretion Controversy}

A hundred years after the discovery of oxygen, a lively controversy agitated the scientific community concerning its transfer from the alveoli to the blood. The question was whether oxygen diffused passively or was actively secreted by the lung towards the blood. At this time, a striking observation had been made in the fish swim bladder which contained a $\mathrm{pO}_{2}$ markedly higher than in the blood. This represented a strong argument favouring active secretion according to Carl Ludwig, Professor of Physiology in Leipzig. The Dane Christian Bohr worked with Ludwig and became convinced by his teacher's postulate. Back in Copenhagen, he became Professor of Medicine and hired the young physiologist August Krogh to work on the secretion of oxygen. August and his wife Marie, a physician, tried to confirm the hypothesis of active secretion but found results opposite to those of Bohr. In 1909, the latter published that $\mathrm{pO}_{2}$ was higher in arterial blood than in the trachea of dogs, an observation supporting the theory of secretion. However, using a new microtonometer, the Kroghs found that $\mathrm{pO}_{2}$ was systematically lower in arterial blood than in alveoli. Unable to reach a fruitful discussion with Bohr on their conflicting data, August and Marie Krogh published a series of articles in 1910, known as the Seven Little Devils, showing that an active secretion was not necessary for oxygen to pass into the blood [20].

This did not extinct the controversy, with Haldane and Douglas supporting active secretion and Barcroft opposing it in Britain [21]. In order to settle the question, Marie Krogh used the inhalation of carbon monoxide (CO), an indifferent gas whose passive diffusion in the lung was not denied. Because of its very high affinity for haemoglobin, $\mathrm{CO}$ partial pressure is negligible in the lung capillary and the alveolo-capillary gradient remains constant, unlike that for oxygen. Under these conditions, the diffusion of $\mathrm{CO}$ across the alveolo-capillary membrane can be calculated from the drop of alveolar CO. In her doctoral thesis in 1914, Marie Krogh was able to demonstrate that diffusion was sufficient to explain oxygen transfer in various conditions [22]. This was the foundation of the nowadays commonly used measurement of CO diffusing capacity $[23,24]$. In retrospect, the high $\mathrm{pO}_{2}$ measured in fish swim bladder is explained by the anaerobic functioning of its cells leading to lactic acid formation. Due to a falling $\mathrm{pH}$, oxygen dissociates from haemoglobin (Root effect), inducing a high plasma $\mathrm{pO}_{2}$ and passive diffusion into the swim bladder $[25,26]$.

Thus, the purpose of breathing has been an enigma taking long to unravel. Numerous examples testify the striking ascendancy of established doctrine upon researchers, hindering logical interpretation of their observations or experiments. In contrast and ironically, fruitful and correct deductions could also stem from a biased premise or methodology.

\section{References}

1 French RK: The thorax in history 1. From ancient times to Aristotle. Thorax 1978;33:1018.

2 Sournia JC: Histoire de la médecine et des médecins. Paris, Larousse, 1991.

3 Proctor DF: Ancient medicine and the mystery of breathing; in Proctor DF (ed): A History of Breathing Physiology. New York, Dekker, 1995, pp 3-16.

4 Derenne JP, et al: The earliest history of diaphragm physiology. Eur Respir J 1994;7: 2234-2240.

5 Wang T: Gas exchange in frogs and turtles: how ectothermic vertebrates contributed to solving the controversy of pulmonary oxygen secretion. Acta Physiol (Oxf) 2011;202:593600.
6 French RK: The thorax in history. 2. Hellenistic experiment and human dissection. Thorax 1978;33:153-166.

7 Proctor DF: Galen: His genius and his shadow; in Proctor DF (ed): A History of Breathing Physiology. New York, Dekker, 1995, pp $17-35$.

8 Derenne JP, et al: History of diaphragm physiology: the achievements of Galen. Eur Respir J 1995;8:154-160.

9 French RK: The thorax in history. 3. Beginning of the Middle Ages. Thorax 1978;3:295306.

10 Mitzner WA: Leonardo and the physiology of respiration; in Proctor DF (ed): A History of Breathing Physiology. New York, Dekker, 1995, pp 37-59.
11 Proctor DF: William Harvey (1578-1657): Blood circulates; in Proctor DF (ed): A History of Breathing Physiology. New York, Dekker, 1995, pp 61-74.

12 French RK: The thorax in history. 5. Discovery of the pulmonary transit. Thorax 1978;33: 555-564.

13 French RK: The thorax in history. 6. Circulation of the blood. Thorax 1978;33:714-727.

14 West JB: Marcello Malpighi and the discovery of the pulmonary capillaries and alveoli. Am J Physiol Lung Cell Mol Physiol 2013;304: L383-L390.

15 Proctor DF: Weighing the air and testing its attributes; in Proctor DF (ed): A History of Breathing Physiology. New York, Dekker, 1995, pp 75-109. 
16 Proctor DF: Breathing the air; in Proctor DF (ed): A History of Breathing Physiology. New York, Dekker, 1995, pp 111-135.

17 Walmsley J: John Locke on respiration. Med Hist 2007;51:453-476.

18 Proctor DF: Mayow's Tractatus Quinque; in Proctor DF (ed): A History of Breathing Physiology. New York, Dekker, 1995, pp 149-166.

19 Chinard FP: Priestley and Lavoisier: oxygen and carbon; in Proctor DF (ed): A History of Breathing Physiology. New York, Dekker, 1995, pp 203-221.
20 Gjedde A: Diffusive insights: on the disagreement of Christian Bohr and August Krogh at the Centennial of the Seven Little Devils. Adv Physiol Educ 2010;34:174-185.

21 Milledge JS: The great oxygen secretion controversy. Lancet 1985;2:1408-1411.

22 Schmidt-Nielsen B: August and Marie Krogh and respiratory physiology. J Appl Physiol Respir Environ Exerc Physiol 1984;57:293303.

23 Hughes JM, Bates DV: Historical review: the carbon monoxide diffusing capacity (DLCO) and its membrane (DM) and red cell (Theta. Vc) components. Respir Physiol Neurobiol 2003;138:115-142.
24 Fitting JW: Transfer factor for carbon monoxide: a glance behind the scene. Swiss Med Wkly 2004;134:413-418.

25 Pelster B: $\mathrm{pH}$ regulation and swimbladder function in fish. Respir Physiol Neurobiol 2004;144:179-190.

26 Berenbrink M, et al: Magnitude of the Root effect in red blood cells and haemoglobin solutions of fishes: a tribute to August Krogh. Acta Physiol (Oxf) 2011;202:583-592. 